\title{
Performance Analysis of Built-in Load Switch in Intelligent Electric Meters
}

\author{
Li Ding ${ }^{1, a}$, Li Li ${ }^{1, b}$, Fan $\mathrm{Li}^{1, \mathrm{c}}$, and Wenjia Cai ${ }^{1, \mathrm{~d}}$ \\ ${ }^{1}$ State Grid Hubei Electric Science \& Research Institute, Hubei Wuhan 430077, China

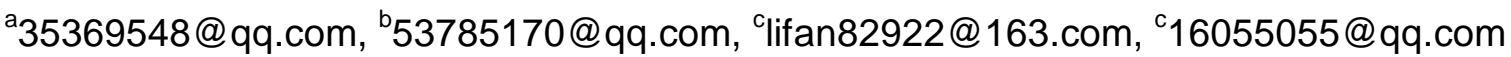

Keywords: Intelligent Electric Meters, Built-in Load Switch, Fault Analysis, Electrode Erosion. Abstract. It is found that some operating faults of the intelligent electric meters are caused by the performance of the built-in load switches. In order to determine the characteristics of the built-in load switches, the performance of the switches are tested and analyzed. The factors, including the complicate operating environment, electrode erosion under short-circuit current, and the control circuit defects, etc. have a great effect on the reliability of the built-in load switches. Under different operating temperatures, the resistance of the control coil is obtained, and it may cause the internal control expires. Faulty conduction of the electrode is caused by the inherent defects, or the electrode erosion under the short-circuit current, and the electrode erosion under pulsed current is presented. The failure of the built-in load switch is mainly determined by the design margin, and some problems are found in the control circuit. It can be concluded that it is beneficial to improve the possibility of fault detection of the built-in loads switches when considering the performance under different conditions. To improve the reliability of the built-in load switch, some technical specifications should be added to the specific content.

\section{Introduction}

The intelligent electric meters are promoted in power company since 2010 . It helps to realize the remote control of the power supply, and it is beneficial to improve the quality of the power supply service. But it should be noted that some failures of the intelligent electric meters have a great effect on the service quality. For example in Hubei province power company, the number of times of the intelligent electric meter malfunction is 28000 in 2013 [1,2]. It is found that $60 \%$ of the malfunctions are caused by the built-in load switches. The performance of the built-in load switches has a significant effect on the reliability of the intelligent electric meters.

For the intelligent electric meters in national grid, $70 \%$ of the load switches are chosen the built-in load switches $[3,4,5]$. Normally the built-in load switches are based on the magnetic latching relays. The relays are designed for the load current less than $60 \mathrm{~A}$, but they always requires to break the higher current $[6,7,8,9]$. The invalidation of the contact system is the dominant failure mode, and $80 \%$ of the failures is caused by the invalidation of the contact system []. Many factors will lead to the invalidation of the contact system, but the contactor erosion caused by arcing discharge is the main factor. So the electrode erosion under high current has some effect on the performance of the built-in load switches. What's more, the intelligent electric meters should be operated in some severe conditions, such as high temperatures, dusty, etc. The performance of the control coil will be effected due to the resistance change under high temperatures. In order to improve the performance of the built-in load switches, the construction of the built-in switches is modified, and more type tests are carried out $[10,11,12]$. Due to the different design and manufacturing techniques of different manufacturers, no consistent conclusion is obtained by the fault detection of the built-in load switches [13, 14].

In order to improve the reliability of the built-in load switches, the factors that affect the characteristics of the switches are analyzed and presented. The factors, including the complicate operating environment, electrode erosion under short-circuit current, and the control circuit defects, etc. have a great effect on the reliability of the built-in load switches. Under different operating temperatures, the resistance of the control coil is obtained. Faulty conduction of the electrode is caused by the inherent defects, or the electrode erosion under the short-circuit current, and the electrode erosion under pulsed current is presented. The failure of the built-in load switch is mainly determined 
by the design margin, and some problems are found in the control circuit. Some technical specifications should be added to the specific content to improve the reliability of the built-in load switch.

\section{Operating Principle of the Built-in Load Switch}

The contactors of the built-in load switch in the latching smart electricity meter is shown in Fig. 1. The close and breaking of the contactors are determined by the electromagnet. The trigger pulse signal with a certain pulse width is sent to the coil, and the contactors complete the close or breaking process under the electromagnetic driving force $[1,9,10]$. As the coil was interpreted by the external disturbance, the operating mode of built-in load switch will be changed, and a failure is appeared. Under some high temperatures, the coil may have the poor performance, such as the decrease of the electromagnetic driving force, and it may lead to the failure of the switch state transition.

In 2016, 66 intelligent electric meters with the faults of the built-in load switches are collected from the Hubei province power company. The failures are detected, and can be divided into four types, including the failure to automatic switch-on, failure to breaking through remote control, failure to close-on through remote control, and failure to breaking with overdue bills. It is found that many factors, such as severe operating conditions, switch quality, electrode erosion, and the control circuit fault, etc. have a great effect on the performance of the built-in load switches.

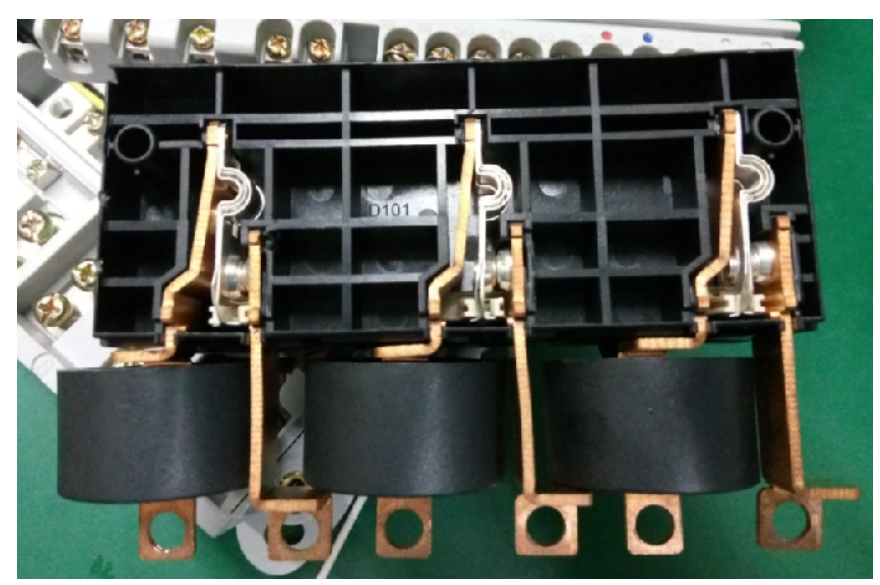

Fig. 1 Contactors of latching smart electricity meter built-load switches

\section{Severe Operating Conditions on the Performance of Built-in Load Switch}

The built-in load switches should be operated reliably with the temperature of $-40^{\circ} \mathrm{C}+85^{\circ} \mathrm{C}$, relative humidity of less than $75 \%$ [2]. Under high temperatures, the resistance of the control coil may be increased, and it causes the decrease of the electromagnetic driving force. The close or breaking failure may occur due to low driving force. So the relationship between the resistance of the coil and the temperature is obtained by the experiments. The test stand is shown in Fig. 2. The built-in load switch is located in a high temperature oven. The resistance is obtained under different environment temperature.

The relationship between the coil resistance and the temperature is shown in Fig. 3. Two built-in load switches are tested. In the normal temperature of $25^{\circ} \mathrm{C}$, the resistance of the coil is about $55.5 \Omega$. As the temperature increases, the coil resistance is found to be proportional to the temperature. When the temperature reaches $85^{\circ} \mathrm{C}$, the resistance is about $58.5 \Omega$. So when the temperature changes from $25^{\circ} \mathrm{C}$ to $85^{\circ} \mathrm{C}$, the relative change of the coil resistance is about $5.4 \%$. It will cause the decrease of the driving force, and may lead to failure action of the built-in load switch. In the design of the control coil, the amplitude of the trigger signal could be increased when considering the resistance changing with the temperature. Then the built-in load switch can be operated reliably in a wide temperature range. 


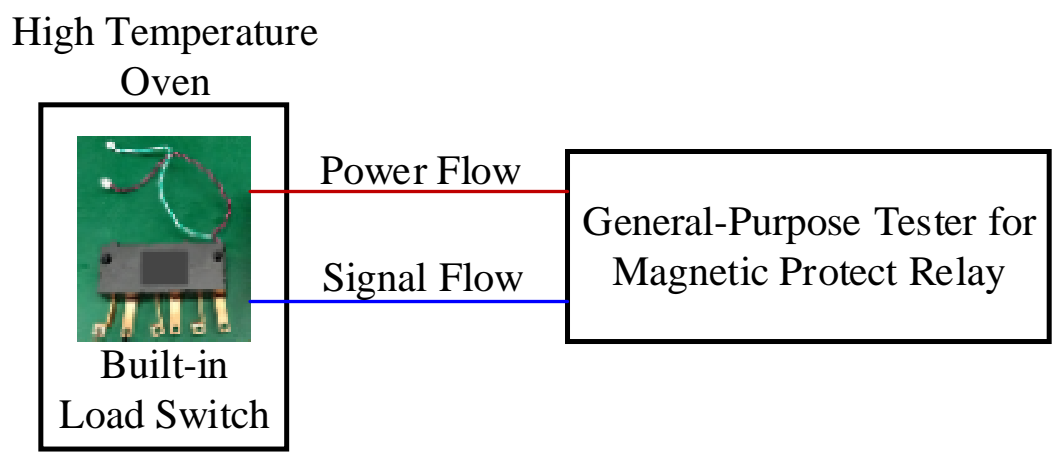

Fig. 2 Resistance test of the control coil

Based on the test results, it can be concluded that the environment temperature is one of the key factors that affect the performance of the built-in load switch. What's more, the construction of the switch will have a little change due to the contraction principle. The insulation material should be chosen the material with the good thermal stability.

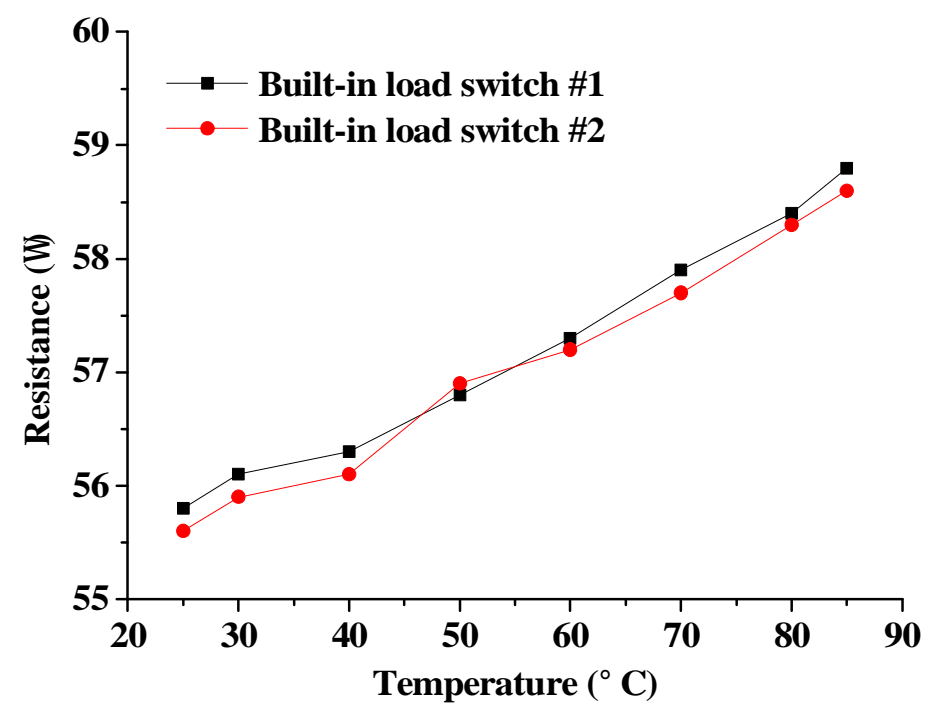

Fig. 3 Relationship between the coil resistance and the temperature

Table 1 Action voltage test of the built-in load switches

\begin{tabular}{c|c|c|c|c}
\hline \multirow{2}{*}{ Type } & \multicolumn{2}{|c|}{ Company I } & \multicolumn{2}{c}{ Company II } \\
\cline { 2 - 5 } & Fault & Normal & Fault & Normal \\
\hline \multirow{3}{*}{ Action } & 8.9 & 5.1 & 9.1 & 4.79 \\
\cline { 2 - 5 } Voltage & 7.9 & 5.7 & 10.1 & 5.3 \\
\cline { 2 - 5 } [V] & 8.3 & 5.3 & 9.3 & 5.1 \\
\cline { 2 - 5 } & 7.9 & 6.2 & 8.7 & 4.8 \\
\cline { 2 - 5 } & 8.7 & 4.7 & 9.5 & 5.3 \\
\hline
\end{tabular}

For the built-in load switch, the rated action voltage is set to $9 \mathrm{~V}$. Normally the action voltage of the built-in load switch should be in the range of 30\% 70\% of the rated action voltage $[8,12]$. Due to the severe operating conditions, some built-in load switch will refuse to close or break because of the low action voltage. It is interesting that the intelligent electric meters always have the different action voltage range, and the probability of the failure varies large. The action voltages of ten fault built-in load switches and ten new built-in load switches are tested and compared. The test results are listed in Table 1. It is found that the fault built-in load switches have the higher action voltage. The action voltage of the new switches is in the range of 52.2\% 68.8\% of the rated action voltage. However, that of the fault switch is in the range of $87.8 \% \sim 112.2 \%$ of the rated action voltage, and it is not satisfied the requirement of Q/GDW11179.8-2015. For this problem, it is mainly depended on the own quality of the switches. Especially, for the different manufacturing techniques of different companies, it is necessary to detect the action voltage of every switch before it is installed. 


\section{Invalidation of Contact System on the Performance of Built-in Load Switch}

For the built-in load switches, the invalidation of the contact system is always appeared. In this investigation of the meter faults, several typical cases are found. The first case is found that a arcing is generated when the switch is closed on. Before the switch action, the load is consuming the power. Then the current is high when the switch is closing on. The arc will move outward due to the magnetic force. The high temperature of the arc (several thousands of ${ }^{\circ} \mathrm{C}$ ) will cause damage of the insulation when arc is moving to the insulation. Seriously it will cause the whole damage of the intelligent electric meter. The second case is that the mechanical properties of the spring and the contact are decreased due to the frequent close and breaking actions. The contact resistance is increased, and is larger than the specified value of less than $2 \mathrm{~m} \Omega$. Then the temperature rise of the contact is increased, and it will accelerate the aging of the around insulation. Then switch fault is gradually generated when it is operated for a long time. The third case is that there is a breaking action when the load is not cut-off completely. The gap is breakdown due to the low withstand voltage of the switch. For the decrease of the withstand voltage, it may be caused by the inherent design defect without the enough margin. And the other reason is caused by the electrode erosion. The surface of the electrode is not smooth after the erosion, and the withstand voltage is decreased largely.

In this paper, the electrode erosion is tested under the pulsed current discharge. The test results are shown in Fig. 4. It is found that the electrode surface is smooth before the test, and the withstand voltage of the gap satisfies the requirement. The discharge currents have the peak value of $2500 \mathrm{~A}$, with the pulse width of $10 \mathrm{~ms}$, and the peak value of $4000 \mathrm{~A}$, with the pulse width of $10 \mathrm{~ms}$. After the $2500 \mathrm{~A} / 10 \mathrm{~ms}$ discharge, the surface is almost smooth, and the withstand voltage of the gap decreases less. The electrode surface has many protrusions after the $2500 \mathrm{~A} / 10 \mathrm{~ms}$ discharge. The electric field in the gap is distorted seriously, and the withstand voltage is decreased obviously.

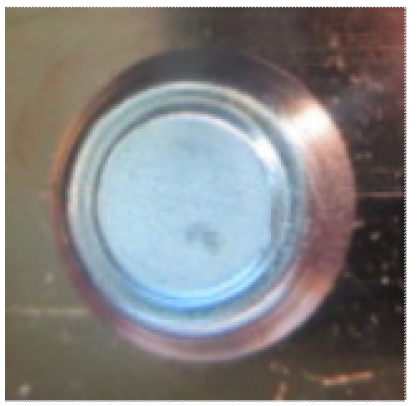

Before test

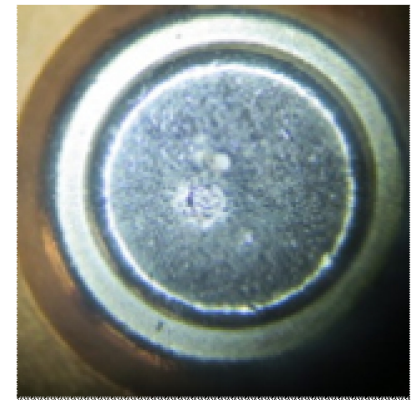

2500A, $10 \mathrm{~ms}$

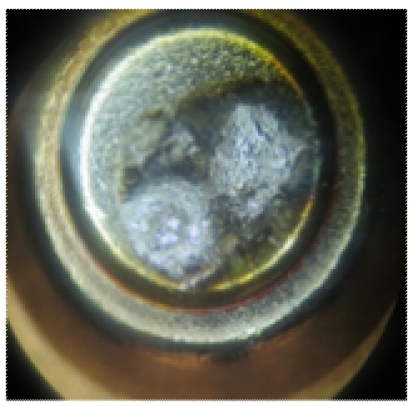

4000A, 10ms

Fig. 4 Electrode erosion under different pulsed current discharge

Under certain discharge pulse width and a given discharge frequency, the erosion rate is approximately proportional to the amount of charge transfer, which implies that the erosion degree is relative to the current duration and the current peak $[15,16,17]$. Winands have studied the erosion characteristics of the brass electrodes in air medium, and found that for one electrode about $40 \mathrm{~cm}^{3}$ is likely to be evaporated with a pulse duration of $100 \mathrm{~ns}$, and a peak-current of $300 \mathrm{~A}$, a total charge transfer of $106 \mathrm{C}$ [18].Currently, there are many types of erosion forms, including ablation, evaporation, oxidation, electronic sputtering, coating or deposition of vaporized metal and disintegration of electrode ionic [19, 20]. The temperature of the arc plasma is always higher than that of the melting point and boiling point of the electrode material. The high-temperature arc will cause the surface of the electrode into the ablation and evaporation. The electrode material undergoes a phase change, causing erosion from the electrode surface. Actually during the high pulsed current discharge, there are several forms of electrode erosion at the same time. For the degradation of the electrodes discharged in gas, the mechanisms include arc joule heating, electrode joule heating, chemical reaction heating, atomic particle interaction, and bulk evaporation, etc.

To improve the erosion characteristics, it is considerable to take the tungsten-copper as the contactor material. As the melting temperature of the copper is much lower than that of the tungsten, 
the copper is easier to be eroded by liquefaction, sputtering or evaporation. It can then be condensed into the electrode surface ahead of the tungsten. Another unique phenomena is that there are obvious arc spots on the surface of the electrodes. Apart from several larger spots on the surface of the anode, average diameters of arc spots on the anode and cathode are almost the same.

\section{Imperfection of Control Circuit on the Performance of Built-in Load Switch}

It should be noted that some faults of the built-in load switch are caused by the software and hardware defects of the control circuit of the intelligent electric meters in this investigation. Normally, the switch is cut-off the load when the defaulting subscriber. Then the user completed the recharge, and the switch should be close on automatically. But sometimes, the switch is refused to complete the action. It is found that it is caused by the mistake program of the control circuit. In some company, the incorrect program is dropped into the control circuit by negligence before the meter is leaving the company. Then the built-in load switch is normal, and did not receive the action command.

Some built-in load switches could not complete the breaking action in the intelligent electric meters. But it is worked when applied a voltage of $9 \mathrm{~V}$ to the control line of the switch. So it is found that there is some problem occurred in the control circuit. It is found that the dynatron in the drive circuit is breakdown, and no trigger signal is sent to the control coil. So it is necessary to improve the margin of the dynatron when considering the cost of the meters.

The hardware flow control of the built-in load switch is shown in Fig. 5. Sometimes the wrong drive signal will be generated due to the external electromagnetic interference. It is necessary to improve the electromagnetic isolation between the strong electricity and the MCU (Micro programmed Control Unit). But it is should be noted that this type fault is not often appeared. The shield of the low voltage circuit could be added if the cost was not increased too much.

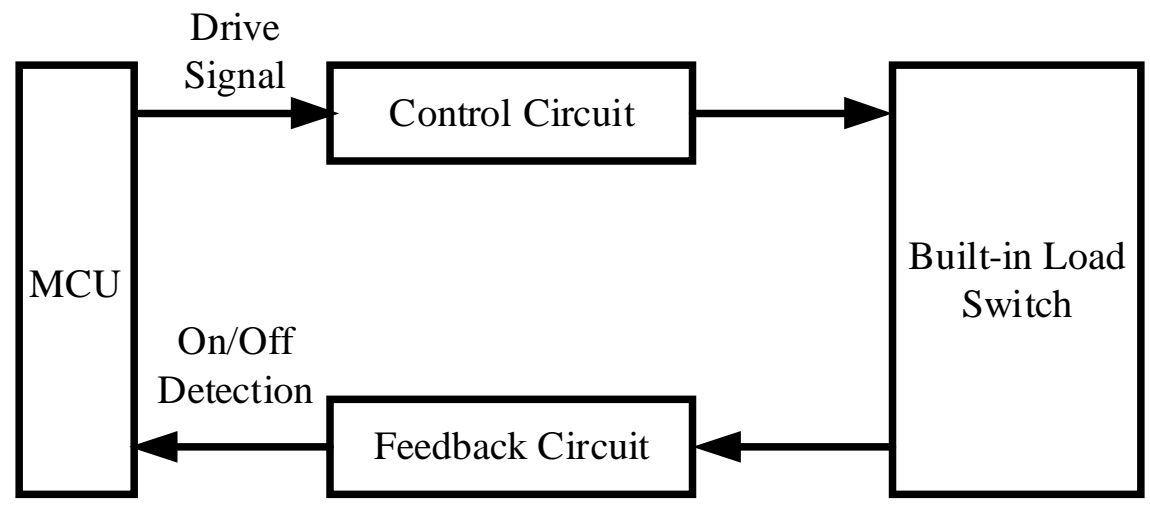

Fig. 5 Hardware flow control of the built-in load switch

\section{Conclusions}

The performance of the built-in load switch is analyzed and presented through the field fault analysis of the intelligent electric meters. The factors, including the severe operating conditions, electrode erosion, and imperfection of the control circuit, etc. are tested by experiments, and have a great effect on the performance of the built-in load switch. Some conclusions can be draw as listed.

The resistance of the control coil increases as the temperature increases, and it may lead to the switch to refuse the action due to the less driving force. Under the over capacity, if the switch could not break the circuit effectively, the whole intelligent electric meter may be damaged from the switch fault initiation. So it is possible to improve the reliable operating range of the built-in load switch in order to obtain a less fault probability.

The electrode erosion has a great effect on the withstand voltage, especially after the heavy load current. To improve the erosion characteristics, it is considerable to take the tungsten-copper as the contactor material. It also need to avoid the arc to damage the around insulation. The mechanical 
construction, including the spring, and the contactor, etc. should be tested rigorously, and the material quality could be improved when comprehensively considering the cost of the switch.

It is necessary to take some measures to isolate the electromagnetic coupling between the high voltage circuit and the low voltage circuit, such as the shielding of the low voltage circuit.

\section{Acknowledgements}

This work was financially supported by the National Power Grid Corp Research Project (JBL17201500227), China.

\section{References}

[1] L. Li, L. Ding, F. Li and W. Cai: Elec. Meas. Tech. Vol. 11A (2014), p. 78.

[2] J. Zhang and X. Gao: Elec. Meas. Instr. Vol. 52 (2015), p. 97.

[3] L. Zhuang, Z. Fu and L. Zhao: Elec. Meas. Instr. Vol. 51 (2014), p. 18.

[4] H. Zhou, G. Fu and Y. Zhou: Elec. Meas. Tech. Vol. 2 (2005), p. 41.

[5] W. Li, M. Yang and Y. Liu: Elec. Meas. Tech. Vol. 49 (2012), p. 141.

[6] F. Ji, X. Guo, Q. Xu and Q. Huang: Elec. Meas. Tech. Vol. 50 (2013), p. 18.

[7] G. Li, B. Li, X. Zhang, Y. Shi and H. Liu: Low Volt. Apparatus Vol. 9 (2011), p. 1.

[8] Y. Dai, Y. Zhang and Y. Shi: Elec. Meas. Tech. Vol. 49 (2012), p. 60.

[9] R. Holm: Electric Contacts: Theory And Applications (Williamson Springer, Germany 1981).

[10] W. Chen, G. Zhang and C. Ke: Low Volt. Apparatus Vol. 9 (2009), p. 1.

[11] Y. Yao, Z. Li and L. Li: Pro. Chi. Soc. Elec. Engineering Vol. 25 (2005), p. 61.

[12]P. Chen, J. Lu and F. Yao: Adv. Tech. Elec. Engineering Vol. 24 (2005), p. 27.

[13]R. Luo, J. Zuo, C. Tian, X. Jiang and Y. Zou: Elec. Meas. Tech. Vol. 11A (2013), p. 1.

[14] Y. Huang, W. Zhou, X. Wu, F. Hu and D. Hao: Elec. Meas. Tech. Vol. 10A (2012), p. 36.

[15]L. Ma and Y. Gan: Ind. Instr. Automation Vol. 1 (2013), p. 42.

[16]Dj.M. Maric, P.F. Meier and S.K. Estreicher: Mater. Sci. Forum Vol. 83-87 (1992), p. 119

[17] A. L. Donaldson, M. O. Hagler, M. Kristiansen and G. Jackson: IEEE Trans. Plasma Sci. Vol. 12 (1984), p. 28.

[18] G. J. J. Winands, Z. Liu, A. J. M. Pemen, E. J. M. V. Heesch and K. Yan: Rev. Sci. Instruments Vol. 76 (2005), p. 085107-1.

[19]P. D. Kumar, S. Kumar, R. Thakur and A. Upadhay: IEEE Trans. Plasma Sci. Vol. 39 (2011), p. 1180 .

[20]R. N. Szente, R. J. Munz and M. G. Drouet: Plas. Chem. Plas. Proc. Vol. 12 (1992), p. 327. 